\title{
Personality disorder in adolescence
}

\author{
Gwen Adshead, Paul Brodrick, Jackie Preston \& Mayura Deshpande
}

\begin{abstract}
SUMMARY
There is considerable debate about the diagnosis of personality disorder in adolescence. It is argued that, because personality is still developing in the teenage years, it is impossible to state with certainty that a young person's personality is disordered. Alternatively, some researchers and clinicians argue that it is possible to diagnose emerging personality disorder on the basis of trait theories of personality. We review the evidence for both sides of the debate.
\end{abstract}

\section{DECLARATION OF INTEREST}

None.

Disorder of personality in adolescence is a complex concept. On the one hand, it may be hard to distinguish personality pathology from normal developmental impermanence and instability. A developmental perspective demands that we keep an open mind about pathology trajectories, and balance resilience against vulnerability factors (Werner 1993). On the other hand, a small subgroup of young people do seem to present with emerging psychopathology that resembles adult personality disorder, where early diagnosis is likely to lead to early interventions and thus improve prognosis. The challenge lies in getting the formulation right. An inaccurate diagnosis of personality disorder in a young person may focus attention away from interventions that improve the caregiving environment at home, or stigmatise a young person in ways which ultimately do more to increase their problems. In this article, we explore these issues in some detail, basing our views on our work in a residential secure unit for young people.

\section{Difficulties in diagnosing personality disorder in adolescents}

A key debate about the diagnosis of personality disorder in adolescents is between those who argue that personality is not fully formed until early adulthood, and those who argue that some personality traits are present and stable from early childhood.

\section{Continuity and traits}

Theories of personality development and continuity from childhood to adulthood are summarised by Caspi et al (2005). Certain clusters of adult traits, such as neuroticism, extraversion, conscientiousness, agreeableness and openness (the socalled 'Big Five' personality traits; Ehrler 1999), have been identified in pre-school children. Their presence in childhood predicts later behaviours (Shiner 2005), suggesting continuity of certain traits. Other studies have described the longitudinal relationship between childhood behaviour and personality traits and adult personality traits (John 1994; Caspi, 2003, 2005; Shiner 2003).

A chief criticism of trait-based personality theory for adolescence is that it seems reductive and does not account for how personalities change over time. Prospective studies of the Big Five traits in children tend to use outcome data based on adult reports, which may reflect adult personality and mood, rather than the childhood trait (Lewis 2001; Kroes 2005).

\section{Change and development}

Personality change from adolescence to adulthood is robustly reported in a variety of lifespan and longitudinal studies (Vaillant 1983; Soldz 1999; Sroufe 2005). There is also evidence that personality traits and diagnoses can change considerably in childhood and early adolescence (10-15 years), but that there is less change and more stability in later adolescence (16-21 years) (Klimstra 2009).

In adolescence, it may be more helpful to think of the personality as a complex organisation of various psychological functions, differentiated into hierarchical levels. It may be that change in adolescence takes place at a different level of personality function, especially at the levels of character adaptations or beliefs and values and cognitions (McAdams 2010; Box 1). The narrative level of the personality is the level of meaning and subjective experience of identity, what McAdams (2008) has called the 'storied self'. Such narratives begin to emerge in late adolescence and are crucially related to the development of a 'moral' identity that makes ethical choices in social groups (Tappan 1989). The development of these moral narrative identities may be relevant to the issue of rule-breaking and conformity in adolescence.

\section{Attachment, abuse and disordered formation of the personality}

Attachment theory-based studies of development have proved relevant to understanding how the
Gwen Adshead is a consultant forensic psychotherapist, Paul Brodrick is principal clinical psychologist, Jackie Preston is a consultant clinical psychologist and Mayura Deshpande is a consultant forensic psychiatrist at Bluebird House, Southern Health NHS Foundation Trust. Bluebird House is a medium secure adolescent treatment service. Correspondence Dr Gwen Adshead, Dadd Centre, Broadmoor Hospital, Crowthorne, Berkshire RG45 7EG, UK. Email: Gwen. adshead@wImht.nhs.uk 
BOX 1 Layers of personality functioning and interventions

Disorders may occur at any level: people with personality disorder typically have high levels of negative traits, limited sense of agency, and impoverished self-narratives characterised by passivity, hostility and a sense of threat.

Layer 1

The person as an actor: traits, dispositions, temperament (limited interventional options: medications for symptomatic relief)

Layer 2

(effective interventions address cognition, values, beliefs, goals, e.g. cognitivebehavioural therapy, dialectical behaviour therapy)

Layer 3

The person as an author: the storied, reflective self (effective interventions address the social and self-reflexive self: group therapies, therapeutic communities, mentalisation-based therapy, cognitive analytic therapy)

The person as an agent: motivations, intentionality, individual characteristics
Johnson and colleagues (1999), who have followed up a large cohort of children in the community into their early 20s. The strength of this research is that it starts from a study of the 'normal', i.e. not those selected because of perceived behavioural difficulties. This research group has shown clearly that childhood maltreatment, including neglect, substantially increases the risk of developing a personality disorder in adolescence (Johnson 2008). They found no difference between genders in terms of the range of maltreatment or the types of personality disorder that develop.

\section{Neurobiology, genes and the development of the personality}

(McAdams 2010)

caregiving environment can produce problematic behaviours in vulnerable children: behaviours that are the basis of the diagnosis of emerging personality disorder. The caregiving environment provided by parents and other adults acts as a growth medium in which the growing child's forebrain will develop through a process of arborisation, dendritisation and neuronal pruning. If the milieu is hostile, frightening or absent through neglect, these neuronal processes are affected (Rice 2000; Schore 2001).

There is a body of evidence linking insecure attachment patterns to various forms of personality pathology (for a review see Sarkar $\&$ Adshead 2006). An important longitudinal study is the Minnesota project by Sroufe et al (2005) which has followed up a high-risk group of children into early adulthood. These authors have focused on childhood as a time of developmental complexity, arguing that successful psychological maturity is associated with high degrees of differentiation and complexity in terms of representations of 'self' and 'other'. In their sample, insecure attachment is strongly associated with the later development of personality pathology in adolescence. This confirmed earlier studies which found that dismissing attachment traits in adolescence is associated with elevated risk of developing traits of narcissistic and antisocial disorders, conduct disorder and substance misuse problems (Rosenstein 1996). In contrast, preoccupied adolescents were more likely to have traits of histrionic, borderline and schizotypal personality disorder.

Childhood and adolescent experience of trauma is also relevant to personality pathology, especially experiences that induce high levels of fear or shame, or both (Lee 2001). Relevant evidence comes from the adolescent community surveys of
There are neurological reasons why diagnosis of personality disorder in children and adolescents may be complex. The brain continues to develop throughout adolescence in terms of myelination and formation of synaptic networks (Rice 2000), which implies that the neural bases for many psychoregulatory systems will still be in development. Such systems will not be fully functional or yet fully 'calibrated' to the individual's needs or environment, and may be expressed as immature psychological defenses such as denial or somatisation (Heilbrunn 1979; Northoff 2007). The development of the frontal lobe may continue to be influenced by the nature of attachment relationships in adolescence, which may be subject to change as parents get older or grandparents die (Sunderland 2006).

Magnetic resonance imaging studies have found that when the brains of adolescents are compared with the brains of young adults there are significant maturational changes in the frontal lobes, temporal and occipital lobes (Sowell 1999). Areas of the brain responsible for response inhibition, emotion regulation, planning and organisation are continuing to develop, hence the increased impulsivity so often seen in adolescence. It has been suggested that adolescents are motivated to take part in novel adult experiences, but lack the contextual knowledge to guide their decision-making, seeming to be more impulsive (Chambers 2003). Adolescent neural networks are also responding to exposure to high levels of sex hormones, with attendant effects on mood regulation. In contrast to pre-school children (where similar struggles with mood and impulse regulation are the norm), language, spatial awareness and sensory functions are largely mature by adolescence (Blakemore 2006).

Yet another problematic aspect of personality disorder diagnosis in childhood and adolescence is revealed by research into gene-environment 
interactions, which indicates that the caregiving environment influences the expression of genetic neuropharmacological vulnerability. For example, studies in boys have found evidence of an interaction between genetic vulnerability and an adverse environment. A hostile caregiving environment makes antisocial behaviour much more likely in boys with variations in allele length for serotonergic proteins than in those without this mutation (Livesley 1993; Caspi 2002; Kim-Cohen 2006).

Finally, given the prevalence of substance misuse among some adolescents, it is vital to consider the relevance of this in relation to psychopathology and diagnosis. Adolescents are motivated to use psychoactive substances that reduce anxiety, increase confidence and allow for attachment to peer groups. The immediate effects of drug and alcohol use on behaviour and social function are well documented, and are a major area of clinical and social work practice. However, the full and long-term extent of the effects of psychoactive substances on forming and developing neural networks, especially in the prefrontal cortex, is not yet known. It is possible that ethanol, in particular, may be neurotoxic to processes such as synaptogenesis or dendritisation, and makes the adolescent brain increasingly vulnerable to environmental challenges that in turn may make adult psychiatric disturbance more likely (Olney 2000).

\section{Emerging personality disorder and child and adolescent mental health services}

The factors discussed in the previous section have two main implications for child and adolescent mental health services (CAMHS). First, if young people's brains are changing, then any psychopathology is also likely to be changing. Therapeutic formulations and diagnoses need to be flexible and responsive to change. Axis I and Axis II disorders are commonly comorbid. In adolescence, this 'transaction' between Axis I and Axis II disorders is likely to be more pronounced, such that each makes the other more likely to develop, and both suggest a vulnerable psychological self-regulating system (Shiner 2009).

The other issue is that the parents' state of mind or beliefs about how they provide care and how the child elicits care are key influences on the child's development and behaviour (Lewis 2001). It is not so much what parents do, as what parents believe about the child and their relationship with him/her that affects children's behaviour. There is evidence that suggests it is the mother's 'mindedness' about the child that affects the way in which the child develops an emotional language and theory of mind that are part of their personality structure
(Meins 1997). Support for the parents is therefore an important aspect of helping young people with emerging personality pathology. In addition, parents of children with conduct or hyperactivity problems are likely to have significant personality pathology themselves. (Wolff 1968; Lahey 1988; Nigg 1997; Kuperman 1999). The most die-hard genetic reductionist must accept that if personality problems are largely genetic, then both the genes and the environment come from the parents. If a child has, for example, callous and unempathic traits, then at least one of the parents probably does too, with potentially dire effects on the caregiving milieu in which the child grows up.

Current thinking about personality disorder favours a dimensional approach to understanding the pathology, i.e. personality disorders are extreme dimensions of normal traits that can vary in severity (Tyrer 1996). If the traits of extraversion, conscientiousness, agreeableness, openness to experience and neuroticism are referred to as the Big Five, then it is possible to conceive of a set of 'Bad Five' traits (Box 2). These would include: avoidance of others and mistrust; impulsiveness and attentional problems; antisocial attitudes and contempt for others; rigidity of thinking and lack of curiosity about anything; and emotional dysregulation resulting in unmodulated and negative affect storms in response to unpredictable stimuli (Shiner 2009).

Shiner (2009) describes how these traits may be manifest in childhood and adolescence in terms of DSM-IV clusters (Table 1). Cluster A involves avoidance, rigidity and variations in reality testing (what Shiner calls the 'peculiar factor'). Cluster C also involves avoidance and internalised emotional dysregulation, characterised by preoccupying anxieties. Cluster B (which, as in adult services, tends to draw most attention) combines antisocial attitudes and contempt for others, impulsivity and emotional dysregulation.

BOX 2 Positive and negative personality traits: Big Five v. Bad Five

$\begin{array}{ll}\text { Big Five } & \text { Bad Five } \\ \text { Found dimensionally in the general } & \begin{array}{l}\text { Found mainly in populations with personality } \\ \text { disorder diagnoses and associated with }\end{array} \\ \text { community } & \text { significant harm: also dimensional } \\ \text { - Extraversion: outgoing personality, } & \text { - Avoidance of others and mistrust } \\ \text { sociability } & \text { - Impulsivity and attentional problems } \\ \text { - Conscientiousness: seeing things through } & \text { - Antisocial attitudes: contempt for social } \\ \text { - Agreeableness: likeability, prosocial } & \text { relations, especially need or vulnerability } \\ \text { stance } & \text { - Rigidity of thought and lack of curiosity } \\ \text { - Openness to experience } & \text { - Emotional dysregulation: unpredictable, } \\ \text { - Neuroticism: anxiety and tendency to } & \text { unmodulated affects when stressed } \\ \text { hyperarousal when stressed } & \end{array}$


TABLE 1 Personality disorder clusters (DSM-IV) and personality traits

\begin{tabular}{|lll|}
\hline Cluster & Personality disorder & Cluster traits \\
\hline Cluster A & Paranoid & Avoidance, rigidity, impairment of \\
& Schizoid & reality testing \\
& Schizotypal & \\
\hline Cluster B & Antisocial & Antisocial attitudes, impulsivity, \\
& Borderline & \\
& Histrionic & \\
& Narcissistic & Avoidance, preoccupied anxiety \\
& Avoidant & \\
\hline Cluster C & Dependent & \\
& Obsessive-compulsive & \\
\hline
\end{tabular}

Source: American Psychiatric Association 1994.

The self-destructive and antisocial aspects of personality disorder are of greatest concern, because they have the potential to cause most distress in adults around the young people, and are therefore most likely to generate referral to CAMHS and/or forensic services. However, children and adolescents are also vulnerable to developing other types of personality dysfunction. Young people with Cluster $\mathrm{A}$ and $\mathrm{C}$ disorders also need interventions, since any Axis II disorder increases the chance of developing an Axis I disorder (Crawford 2008). In addition, any personality disorder in adolescence increases the risk of violent acting out, with potentially disastrous consequences for the young person (Johnson 2000).

\section{Prevalence of personality disorder in children and adolescents}

Despite scepticism about whether personality disorder can really exist in children, there are studies which indicate that personality disorder diagnoses in adolescents have validity and stability over time (Brent 1990; Bernstein 1993; Levy 1999).

The personality disorders that present to adolescent services appear to resemble those that present to adult services. As always, prevalence rates are affected by selection bias in relation to services selected for study, and the recruitment of participants. For example, the Bernstein et al(1993) study of personality disorder in a communitybased sample of children and adolescents found a prevalence of $31 \%$ : the most common of which was obsessive-compulsive personality disorder. Only $17 \%$ of the cohort had a severe disorder; most commonly narcissistic personality disorder. By contrast, Levy et al (1999) found that $61 \%$ of an adolescent in-patient sample had a Cluster B personality disorder, mainly borderline personality disorder. There were very few patients with Cluster C diagnoses. Neither study screened for antisocial personality disorder.
Kasen et al (1999) completed a prospective longitudinal study of personality pathology in children aged 9-13 years over three follow-up points in a 10-year period. Their prevalence data indicate that about $15 \%$ of adolescents had a Cluster B personality disorder before young adulthood. Prevalence rates were comparable across genders. The prevalence of personality disorder at the start of the study was $9.6 \%$ for Cluster A, $16.7 \%$ for Cluster B, and $8.2 \%$ for Cluster C. However, the prevalence of the disorders changed over time: for example, at the start of the study, $7.6 \%$ of boys and $9.4 \%$ of girls had a Cluster B diagnosis, but 9 years later, the prevalence was $22.4 \%$ of boys and $11.9 \%$ of girls. The prevalence had increased in both genders, but considerably more for the boys.

Most studies of personality disorder in in-patient settings focus on Cluster B disorders: borderline or antisocial psychopathology. We have reviewed some of the data on antisocial personality symptoms here, but emphasise that other personality psychopathology may be emergent in adolescence yet ignored because it does not cause social disruption.

\section{Emerging antisocial personality traits and related disorders}

Conduct disorder in children, antisocial personality disorder and psychopathy are interrelated but are distinct clinical concepts. There has been considerable interest in the relationship of early childhood behavioural problems and later antisociality since the early studies of Robins (1966) showed that a small subgroup of children with conduct disorder show persistently antisocial behaviour in adulthood. The diagnosis of antisocial personality disorder requires evidence of childhood history of rule-breaking and irresponsibility.

Frick and colleagues (Frick 1994; Salekin 2005) demonstrated that children with severe behavioural disturbance can sometimes show callous-unemotional traits, and that these traits are different from traits from the behavioural definitions for conduct disorder. Frick (1998) suggested that the co-existence of attention-deficit hyperactivity disorder, childhood-onset conduct disorder and callous-unemotional traits is highly correlated with the construct of psychopathy. However, there is no empirical data supporting the progression of these factors into adult psychopathy, which is characterised by affective deficits, multiple forms of criminality and increased risk of severe violence (Frick 2002).

Farrington $(2005 \mathrm{a}, \mathrm{b})$ reports a prospective study of 400 boys up to adulthood using the Hare 
Psychopathy Checklist Screening Version (PCLSV). His group found that high PCL-SV scores at age 48 years were predicted by childhood environmental (rather than personality) factors between ages 8 and 10, including physical neglect, poor parental supervision, a disrupted family, large family size, a convicted parent, and a mother with depression. Such studies confirm the importance of childhood adversity as a good predictor of later antisociality, and being as important as any genetic influence.

Delinquency in young women is often overlooked. In a meta-analytic review, Fontaine et al (2009) examined 46 empirical studies that examined the developmental trajectories of antisocial behaviour in females. They found similar trajectories to the adolescent male research, with the addition of a further category, adolescent-delayed onset, where females had apparently not shown antisocial behaviour until later in adolescence. The emergence of antisocial behaviour at this time was considered to be associated with a decrease in familial and school control over the young women, an association with delinquent peer groups and hormonal changes due to puberty. Caspi et al (1993) suggest that there may be specific biological risk factors for delinquency in women (e.g. early menarche).

\section{Offending and personality disorder in adolescents}

The peak age for minor offending is $17-18$ and so it is not unusual to find an adolescent male who has committed an offence. However, there is a subgroup of adolescent offenders who commit the majority of offences. These can be divided into:

- those who behave antisocially only during adolescence (and effectively 'grow out' of their antisocial behaviour);

- those that persist in acting antisocially as they get older.

Research into offending trajectories indicates that only $5-10 \%$ of adolescents who show antisocial characteristics follow the trajectory into adulthood. They are referred to as the early-onset life course group (Moffitt 2001; Laub 2003). This group are clinically distinct and have a poorer prognosis when compared with the adolescencelimited group, who engage in antisocial behaviour for only a limited period during adolescence. The latter are believed to show antisocial behaviour as a part of gaining independence, seeking status and becoming free of parental supervision.

The evidence indicates that the early-onset group have experienced severe family adversity and a coercive parenting style (Moffitt 2001). This group are thought to be exposed to severe environmental adversity over a prolonged period of time. A follow-up study of males who had been aggressively antisocial in childhood, but had shown little delinquency in adolescence, reported that at age 26 they tended to be socially isolated and to have adjustment and mood problems and financial difficulties, rather than severe antisocial behaviour per se (Moffitt 2002).

Vizard et al(2004) propose the existence of severe personality disorder in children and adolescents, on the basis of studies of the characteristics of young people who have committed sexual assaults or other serious crimes. They hypothesise that callous and unemotional personality traits arise as a consequence of a combination of genetic, perinatal and early developmental difficulties which become progressively more disabling as the individual matures. The authors outline a multifactorial pathway for the development of severe personality disorder involving early attachment difficulties, poor peer relationships, and early and serious child abuse, which are then manifest as aggression and sexualised behaviours in childhood. They emphasise the therapeutic importance of early detection.

\section{Assessment of personality in childhood and adolescence}

Given that the diagnostic process is complex for adolescents, it is not clear whether assessment tools that are based on adult assessment of personality disorder will be either valid or reliable. Nor is it clear whether there is value in assessment tools that are standardised on clinical populations. In children, both temperament and behaviour can be assessed using a variety of tools, although these are rarely used outside research protocols. Most research studies of emerging personality pathology have utilised assessment tools based on adult assessment tools (Shiner 2003). There is uncertainty about the use of such tools in ordinary clinical services.

However, some specialist services for adolescents do use personality assessment tools (Box 3). These include the NEO Personality Inventory - Revised (NEO-PI-R; Costa 1992), which assesses Big Five traits in adolescents (De Clercq 2003; Allik 2004), and the Millon Adolescent Clinical Inventory (MACI; Millon 2006). The MACI is a self-report measure based on the Millon Clinical Multiaxial Inventory. Constructs have been validated against DSM-IV diagnostic criteria and address three different types of reported difficulties: personality trait, expressed concerns and behaviours. 
BOX 3 Some personality disorder assessment tools used in adolescence

- Hare Psychopathy Checklist - Youth Version: young people's version of standard measure of psychopathy (Forth 2005)

- Millon Adolescent Clinical Inventory: developed to be used in teenagers (Millon 2006)

- Minnesota Multiphasic Personality Inventory Adolescence (MMPI-A): an empirically based measure of adolescent psychopathology (Butcher 2006)

- NEO Personality Inventory - Revised: a general measure of Big Five personality traits (Costa 1992)

Measures of attachment may be helpful in terms of making sense of personality pathology and suggesting interventions in family dynamics. A variety of measures of both attachment and personality disorder in adolescents are described by Westen et al (2006).

Forensic CAMHS and some youth offender services use youth versions of risk assessment instruments, such as the Hare Psychopathy Checklist - Youth Version (PCL-YV; Forth 2005) and the Structured Assessment of Violence Risk in Youth (SAVRY; Borum 2005). There are ethical concerns about their routine use because they can be used in stigmatising ways that reduce young people's access to general adolescent services.

\section{Management of adolescent personality disorder}

Work with children and adolescents differs from that with adults, in that services take a more systemic approach. An especially significant difference from adult services is the statutory involvement of the education system, and the need to work with family members who are still involved in the young person's social network. However, the treatment of a young person with an emerging personality disorder should follow the principles of CAMHS generally. In particular, it is important to screen for Axis I disorders such as depression or psychotic disorders, especially in children and adolescents with emerging borderline personality disorder where depression is likely to be a comorbid condition.

Specific interventions for personality disorder in adolescents are similar in principle to those for adults, although few have been subjected to the same level of empirical evaluation. The National Institute for Health and Clinical Excellence (NICE) guidelines for borderline personality disorder noted that there has been only one published randomised controlled trial of interventions for adolescents with personality disorder, which may be because clinicians are reluctant to diagnose young people with the disorder (National Collaborating Centre for Mental Health 2009a). Similarly, there is no mention of any evidence relating to the treatment of comorbid personality disorders in young people with depression or eating disorders, even though these are common comorbidities in adulthood. Such a lack of evidence makes treatment complex, especially since the transition between adolescence and adulthood may be a critical period for intervention.

\section{Dialectical behaviour therapy}

Dialectical behaviour therapy (DBT) has been adapted for a wide range of clinical populations, including adolescents. Programmes offering DBT to adolescents have been adapted in a number of ways, but no one version has been shown to be superior.

There is preliminary evidence to support an adapted version of DBT with adolescents who meet criteria for borderline personality disorder (Rathus 2002). Adolescent DBT (DBT-A) differs from adult DBT in that it is designed to be delivered over fewer sessions (24 sessions over 12 weeks, compared with typically weekly sessions over 12 months for adults), includes parents in the therapy programme, places a greater emphasis on the family, and focuses on teaching a smaller number of skills. The language used is adapted to be more appropriate for an adolescent (Rathus 2002).

Involvement of the family or carers in skills training is common to many of these adaptations. Teaching other family members skills can enable them to act as skills coaches to generalise these skills in young person's everyday environment. Although individuals are encouraged to work towards changing their own environment during DBT, it is recognised that adolescents may not always have the autonomy to effect these.

Rathus \& Miller (2002) found that adolescents engaging in DBT were admitted to hospital less often, had higher rates of treatment completions, reduction in suicidal ideation and symptoms of borderline personality disorder when compared with treatment as usual. There was a significant reduction in behavioural incidents when DBT was used on an adolescent in-patient unit, when compared with a unit run on psychodynamically oriented principles (Katz 2004). James et al (2011) offered DBT to a community sample of adolescents in the 'looked after' system (i.e., in the care of the Local Authority). The authors found a significant reduction in self-report depression scores (Beck 
Depression Inventory), hopelessness (Beck Hopelessness Scale) and episodes of self-harm.

Dialectical behaviour therapy has also been shown to have some positive effects in female juvenile rehabilitation settings (Trupin 2002). This study highlighted both the impact of DBT on the young people and changes in the staff's reactions to them. Staff who had completed indepth training in DBT showed a reduction in punitive interventions.

\section{STEPPS}

Another programme for improving emotion regulation is Systems Training for Emotional Predictability and Problem Solving (STEPPS; Blum 2009). This has been used with adolescents to good effect (Schuppert 2009). Compared with treatment as usual, adolescents who completed the STEPPS programme reported feeling a greater sense of control over their mood swings. The STEPPS programme, like DBT-A, involves training not just the young persons, but also family, friends and professionals with a shared understanding of the skills, so that the network of people closest to the young person can learn to reinforce and support the newly acquired skills.

\section{Treatments for conduct disorder}

A variety of interventions for conduct disorder have been evaluated both in the USA and the UK (Breston 1998; National Collaborating Centre for Mental Health 2009b). These include parent training, cognitive problem-solving training with young people, programmes that combine work with parents and children, family therapy, and treatment in foster care. All these interventions have been shown to be effective for selected groups. Family therapy and treatment in foster care have both been found to reduce behaviour problems and offending. There is a large evidence base for groupbased training programmes for parents, probably due to an effect on parental negativity towards their child.

\section{Multisystemic therapy}

Multisystemic therapy is used with children and adolescents at risk of antisocial behaviours. It has been subject to a number of treatment trials, and shown to be effective with selected groups of young people and their families. It is a family- and community-based treatment programme, with the aim of improving communication, parenting skills, prosocial peer relationships, school performance and social networks. The outcome is to keep young people in their family homes rather than incarcerated in prison settings or hospitals (Henggeler 1992; Littell 2005). Families have reported increased family cohesion, and young people have fewer arrests and self-reported offences.

\section{Are psychological therapies effective?}

It is possible to provide adolescents with psychological interventions that improve problematic behaviours. However, it is not clear whether these interventions effect change in underlying personality structures. Given the importance of insecure attachment for the development of disordered personalities, it seems important to provide a secure base for therapy, and to promote curiosity and learning of new cognitions and appraisals, both of self and others. Young people with different attachment styles may present with different symptom profiles and behavioural challenges.

\section{Conclusions and questions}

It seems clear that for a small number of adolescents, a diagnosis of personality disorder can be confidently made. There is significant health morbidity among affected adolescents. Just as for adults, young people who have a personality disorder have high rates of early mortality, especially among those with borderline personality disorder and antisocial personality disorder (Kjelsberg 1998; Pajer 1998). Therefore, these disorders are deserving of more time and attention from researchers, clinicians and policy makers.

However, the diagnosis of personality disorder is a double-edged sword (Box 4). Although early identification and treatment are likely to ameliorate a lifetime of potential suffering for the individual and society, a personality disorder diagnosis is a

BOX 4 Pros and cons of personality disorder diagnosis

\begin{tabular}{|c|c|}
\hline Pros & Cons \\
\hline - Early diagnosis means early intervention & - Tendency of personality disorder \\
\hline $\begin{array}{l}\text { - Improved diagnosis means improved } \\
\text { treatment planning and implementation }\end{array}$ & $\begin{array}{l}\text { diagnoses to 'stick' and not be revised as } \\
\text { the young person changes }\end{array}$ \\
\hline $\begin{array}{l}\text { - The personality disorder diagnosis reflects } \\
\text { a developmental account of the young } \\
\text { person and their experience }\end{array}$ & $\begin{array}{l}\text { - People with personality disorder } \\
\text { diagnoses are often refused access to } \\
\text { services }\end{array}$ \\
\hline $\begin{array}{l}\text { - Personality disorder is a real disability: we } \\
\text { may contribute to stigma and myths if we } \\
\text { do not name it when we need to }\end{array}$ & $\begin{array}{l}\text { - The diagnosis is a stigmatising label, and } \\
\text { puts the young person at risk of rejection } \\
\text { by services and ignorant professionals }\end{array}$ \\
\hline $\begin{array}{l}\text { - There are effective treatments for } \\
\text { personality disorder }\end{array}$ & $\begin{array}{l}\text { - The diagnosis does not reflect the trauma } \\
\text { histories in young people }\end{array}$ \\
\hline & $\begin{array}{l}\text { - It is pointless to make a diagnosis where } \\
\text { there is no treatment service }\end{array}$ \\
\hline
\end{tabular}


stigmatising label that can follow a young person for a considerable time and paradoxically block their access to treatment and services (Castillo 2000). An alternative lexicon has sprung up in recent decades, with clinicians appearing to prefer to use diagnoses that emphasise trauma rather than challenging behaviours, such as the widespread use of the term 'complex post-traumatic stress disorder' instead of emerging borderline personality disorder, particularly when there is a history of prolonged trauma as an antecedent. Similarly, young people with significant antisocial traits continue to be labelled as having conduct disorder or mixed disorder of conduct and emotions or even reactive attachment disorder, rather than antisocial personality disorder.

This approach illustrates the continuing reluctance of clinicians to diagnose personality disorder in young people whose personalities are still developing. Clearly, it is unprofessional to use diagnoses in thoughtless and unhelpful ways, and it is valuable to promote recovery and coping skills in all mental disorders, including personality disorder. The difficulty with not using the personality disorder diagnosis is that it may obscure clinical need, often in relation to the most difficult symptoms such as hostility and rage attacks. It may also allow professionals to avoid looking at their own negative reactions to difficult young people, especially those who have been cruel or hostile to others.

Whichever diagnostic descriptors are used, clinicians are likely to meet young people with symptoms and signs of antisocial or borderline personality disorder. Therefore there must be more debate and consensus on which descriptive diagnoses are most useful. A move from purely categorical to more dimensional diagnostic systems would help to overcome this. Adolescents with these syndromes must not be denied interventions and treatments merely because of the fears of labelling and perpetuation of stigma.

There are a number of research questions to pursue. The principal of these regard the prevention of antisocial personality disorder in adolescence and the identification of high-risk cases (Harrington 2004). We also do not know why girls subjected to trauma are more likely to develop borderline personality disorder, whereas boys are likely to develop conduct disorder and eventually antisocial personality disorder. Nor can we identify which young people will present with which disorder, at which point in their lives and why. Related to this are ethical questions about identifying children and adolescents as being at 'high risk' or antisocial, especially on the basis of their genes.
Research in the area of personality disorder in the young is bound to focus on the aetiology and pathogenesis of these disorders. In recent years, gene-environment interactions have received increasing attention as efforts are made to unravel the complex interplay between them. However, future research must focus on bridging the gap between gene and environment since a purely genetic or purely environmental view is unlikely to provide the answer. Since it is also unlikely that we will be able to alter genetic profiles any time soon, we may be under an extra duty to intervene in children's adverse environments.

On this basis, services should be designed to intervene early and with the adolescent's environment - the home, school and neighbourhood. Therapeutic interventions for children and adolescents must focus on helping to increase their resilience as much as on treating the disorder, and on the development of a prosocial identity. The emphasis must shift to the preventive, in the form of interventions for parents and caregivers. Environmental adversity in childhood increases the risk of the development of a whole range of problems (Axis I and Axis II disorders) in childhood and adolescence that may persist into adulthood. These disorders are costly, not only for the young people and their families but for all of us.

\section{References}

Allik J, Laidra K, Realo A, et al (2004) Personality development for 12-18 years of age: changes in mean levels of and structures of traits. European Journal of Personality 18: 445-62.

American Psychiatric Association (1994) Diagnostic and Statistical Manual of Mental Disorders (4th edn) (DSM-IV). APA

Bernstein D, Cohen P, Velez N, et al (1993) Prevalence and stability of the DSM-III-R personality disorders in a community survey of adolescents. American Journal of Psychiatry 150: 1237-42.

Blakemore SJ, Choudhury S (2006) Development of the adolescent brain: implications for executive function and social cognition. Journal of Child Psychology and Psychiatry 47: 296-312.

Blum NS, Bartels NE, St John D, et al (2009) Systems Training for Emotional Predictability and Problem Solving (STEPPS - UK Version): Group Treatment Program for Borderline Personality Disorder. Level One Publishing (http://www.steppsforbpd.com).

Borum R, Bartel P, Forth A (2005) Structured assessment of Violence Risk in Youth (SAVRY). In Mental Health Screening and Assessment in Juvenile Justice (eds T Grisso, G Vincent, D Seagrave): 311-23. Guilford Press.

Brent D, Zelenak J, Bukstein 0, et al (1990) Reliability and validity of structured interviews for personality disorder in adolescence. Journal of the American Academy of Child \& Adolescent Psychiatry 29: 349-54.

Breston E, Eyber S (1998) Effective psychosocial treatment of conduct disordered children: 29 years, 82 studies and 5,272 kids. Journal of Clinical Child Psychiatry 27: 180-9.

Butcher J, Williams CL, Graham JR, et al (2006) Minnesota Multiphasic Personality Inventory - Adolescence. Pearson Education.

Caspi A, Lynan D, Moffitt T, et al (1993) Unravelling girls' delinquency: biological, dispositional and contextual contributions to adolescent misbehaviour. Developmental Psychology 29: 19-30. 
Caspi A, Harrington H, Milne B, et al (2003) Children's behavioural styles at age 3 are linked to their adult personality traits at age 26. Journal of Personality 71: 495-514.

Caspi A, Roberts B, Shiner R (2005) Personality development: stability and change. Annual Review of Psychology 56: 453-84.

Caspi A, McClay J, Moffitt T, et al (2002) The role of the genotype in the cycle of violence in maltreated children. Science 297: 851-4.

Castillo H (2000) Personality Disorder: Temperament or Trauma? Jessica Kingsley.

Chambers RA, Taylor RP, Potenza MN (2003) Developmental neurocircuitry of motivation in adolescence: a critical period of addiction vulnerability. American Journal of Psychiatry 160: 1041-52.

Costa P. McCrae R (1992) Revised NEO Personality Inventory (NEO-PI-R) and the NEO Five-Factor Inventory Professional Manual. Psychological Assessment Resources.

Crawford T, Cohen P, First M, et al (2008) Comorbid Axis I and Axis II disorders in early adolescence. Archives of General Psychiatry 65: 641-8.

De Clercq B, De Fruyt F (2003) Personality disorder symptoms in adolescence: a five factor model perspective. Journal of Personality Disorders 17: 269-92.

Ehrler D, Evans JG, McGhee RL (1999) Extending Big-Five theory into childhood: a preliminary investigation into the relationship between BigFive personality traits and behavior problems in children. Psychology in the Schools 36: 451-8.

Farrington D (2005a) The importance of child and adolescent psychopathy. Journal of Abnormal Child Psychology 33: 489-97.

Farrington D (2005b) Childhood origins of antisocial behavior. Clinical Psychology \& Psychotherapy 12: 177-90.

Fontaine N, Carbonneau R, Vitaro F, et al (2009) Research review: a critical review of studies on the developmental trajectories of antisocial behaviour in females. Journal of Child Psychology and Psychiatry 50: 363-85.

Forth A (2005) The Hare Psychopathy Checklist - Youth Version. In Mental Health Screening and Assessment in Juvenile Justice (eds T Grisso, G Vincent, D Seagrave): 324-36. Guilford Press.

Frick P, O'Brien B, Wootton J, et al (1994) Psychopathy and conduct problems in children. Journal of Abnormal Psychology 103: 700-7.

Frick P (1998) Callous/unemotional traits and conduct problems: applying the two-factor model of psychopathy to children. In Psychopathy: Theory, Research and Implications for Society (eds DJ Cooke, AR Forth \& RD Hare): 161-87. Kluwer Academic.

Frick P (2002) Developmental pathways to conduct disorder: implications for servicing youth who show severe and aggressive antisocial behaviour. Psychology in the Schools 41: 823-34.

Harrington R, Bailey S (2004) Prevention of antisocial personality disorder: mounting evidence on optimal timings and methods. Criminal Behaviour and Mental Health 14: 75-81.

Heilbrunn G (1979) Neurobiologic correlates with defense mechanisms and psychotherapy. American Journal of Psychotherapy 33: 547-54.

Henggeler S, Melton G, Smith L (1992) Family preservation using MST: an effective alternative to incarcerating serious juvenile offenders. Journal of Consulting and Clinical Psychology 60: 953-61.

James AC, Winmill L, Anderson C, et al (2011) A preliminary study of an extension of a community dialectic behaviour therapy (DBT) programme to adolescents in the looked after care system. Child \& Adolescent Mental Health 16: 9-13.

John 0, Caspi A, Robins R, et al (1994) The 'Little five': exploring the nomological network of the five-factor model of personality in adolescent boys. Child Development 65: 160-78.

Johnson J, Cohen P, Brown J, et al (1999) Childhood maltreatment increases the risk for personality disorders during early adulthood. Archives of General Psychiatry 56: 600-6.

Johnson J, Cohen P, Smailes E, et al (2000) Adolescent personality disorder is associated with violence and criminal behaviour during adolescence and early adulthood. American Journal of Psychiatry 157 : $1406-12$.

Johnson J, Cohen P, Kasen S, et al (2008) Psychiatric disorders in adolescence and early adulthood and risk for child rearing difficulties during middle adulthood. Journal of Family Issues 29: 210-33.

Kasen S, Cohen P, Skodol A, et al (1999) Influence of child and adolescent psychiatric disorders on young adult personality disorder. American Journal of Psychiatry 156: 1529-35.

Katz L, Cox B, Gunasekara S, et al (2004) Feasibility of DBT for suicidal adolescent inpatients. Journal of the American Academy of Child \& Adolescent Psychiatry 43: 276-82

Kim-Cohen J, Caspi A, Taylor A, et al (2006) MAOA, maltreatment, and gene-environment interaction predicting children's mental health: new evidence and a meta-analysis. Molecular Psychiatry 11: 903-13.

Kjelsberg D, Dahl AA (1998) High delinquency, disability and mortalityregister study of former adolescent psychiatry. Acta Psychiatrica Scandinavica 98: 34-40.

Klimstra TA, Hale WW, Raaiimoken OA (2009) Maturation of personality in adolescence. Journal of Personality, Society \& Psychology 96: 898-912.

Kroes G, Verman JW, Der Bruyn EE (2005) The impact of the Big 5 traits on reports of child behaviour by different informants. Journal of Abnormal Child Psychology 33: 231-40.

Kuperman S, Schlosser S, Lidral J, et al (1999) Relationship of child psychopathology to parental alcoholism and antisocial personality disorder. Journal of the American Academy of Child \& Adolescent Psychiatry 27: 163-70

Lahey BB, Piacentini JC, McBurnett K, et al (1988) Psychopathology in the parents of children with conduct disorder and hyperactivity disorder. Journal of the American Academy of Child \& Adolescent Psychiatry 27 : 163-70.

Laub J, Sampson R (2003) Shared Beginnings, Divergent Lives: Delinquent Boys to Age 70. Harvard University Press.

Lee DA, Scragg P. Turner S (2001) The role of shame and guilt in traumatic events: a clinical model of shame-based and guilt-based PTSD. British Journal of Medical Psychology 74: 451-66.

Levy K, Becker D, Grilo C, et al (1999) Concurrent and predictive validity of the personality disorder diagnosis in adolescent inpatients. American Journal of Psychiatry 156: 1522-8.

Lewis ML (2001) On the development of the personality. In Handbook of Personality: Theory and Research (2nd edn) (eds LA Pervin, OP John): 327-46. Guilford Press.

Littell J (2005) Lessons from a systematic review of effects of multisystemic therapy. Child and Youth Service Review: 27: 445-63.

Livesley WJ, Jang KL, Jackson DN, et al (1993) Genetic and environmental contributions to dimensions of personality disorder. American Journal of Psychiatry 150: 1826-31.

McAdams D (2008) Personal narratives and the life story. In Handbook of Personality: Theory and Research (3rd edn) (eds 0 John, RW Robins, LA Pervin): 242-62. Guilford Press.

McAdams D, Olsen B (2010) Personality development: continuity and change over the life course. Annual Review of Psychology 61: 517-42.

Meins E (1997) Security of Attachment and the Social Development of Cognition. Psychology Press.

Millon T, Millon C, Davis R, et al (2006) Millon Adolescent Clinical Inventory Manual (MACl) (2nd edn). Pearson Education.

Moffitt TE, Caspi A (2001) Childhood predictors differentiate life-course persistent and adolescent limited antisocial pathways among males and females. Development and Psychopathology 13: 355-75.

Moffitt TE, Caspi A, Harrington H, et al (2002) Males on the life-coursepersistent and adolescence-limited antisocial pathways: follow-up at age 26 years. Developmental Psychopathology 14: 179-207.

National Collaborating Centre for Mental Health (2009a) Borderline Personality Disorder: Treatment and Management (Clinical Guideline CG78). National Institute for Health and Clinical Excellence.

\section{MCO answers}

1 e $\quad 2$ c $\quad 3 d \quad 4 d \quad 5$ a 
National Collaborating Centre for Mental Health (2009b) Antisocial Personality Disorder: Treatment, Management and Prevention (Clinical Guideline CG77). National Institute for Health and Clinical Excellence.

Nigg JT, Hinshaw SP (1997) Parent personality traits and psychopathology associated with antisocial behaviors in childhood ADHD. Journal of Child Psychology \& Psychiatry 39: 145-59.

Northoff G, Bermpohl F, Schoeeich F, et al ( 2007) How does our brain constitute defense mechanisms? First person, neuroscience and psychoanalysis. Psychotherapy \& Psychosomatics 76: 141-53.

Olney J, Farber NB, Wozniak DF, et al (2000) Environmental agents that have the potential to trigger massive apopototic neurodegeneration in the developing brain. Environmental Health Perspective 108 (suppl 3): 383-8.

Pajer K (1998) What happens to 'bad' girls? A review of the adult outcomes of antisocial adolescent girls. American Journal of Psychiatry 55: 862-77.

Rathus JH, Miller AL (2002) Dialectical behavior therapy adapted for suicidal adolescents. Suicide \& Life-Threatening Behavior 32: 146-57.

Rice D, Barone Jr S (2000) Critical periods of vulnerability for the developing nervous system: evidence from humans and animal models. Environmental Health Perspectives 108 (suppl 3): 511-33.

Robins LN (1966) Antisocial Children Grown Up: A Sociological and Psychiatric Study of Sociopathic Personality. Williams \& Wilkins.

Rosenstein DS, Horowitz HA (1996) Adolescent attachment and psychopathology. Journal of Consulting and Clinical Psychology 64: 244-53.

Salekin RT, Frick PJ (2005) Psychopathy in children and adolescents: the need for a developmental perspective. Journal of Abnormal Child Psychology 33: 403-9.

Sarkar J, Adshead G (2006) Personality disorders as disorganisation of attachment and affect regulation. Advances in Psychiatric Treatment 12: 297-305.

Schore A (2001) The effect of early relational trauma on right brain development, affect regulation and infant mental health. Infant Mental Health Journal 22: 201-69.

Shiner RL, Masten AS, Roberts JM (2003) Childhood personality foreshadows adult personality and life outcomes two decades later. Journal of Personality 71: 1145-70.

Shiner R (2005) A developmental perspective on personality disorders. Journal of Personality Disorders 19: 202-10.
Shiner R (2009) The development of personality disorders: perspectives from normal development. Development and Psychopathology 4: 715-34

Shiner R, Caspi A (2003) Personality differences in childhood and adolescence: measurement, development and consequences. Journal of Child Psychology \& Psychiatry 44: 2-32.

Schuppert HM, Giesen-Boo J, van Gemert TG, et al (2009) Effectiveness of an emotion regulation group training for adolescents: a randomised controlled pilot study. Clinical Psychology \& Psychotherapy 16: 467-78.

Sroufe A, Egeland B, Carlson E, et al (2005) The Development of the Person: The Minnesota Study of Risk and Adaptation from Birth to Adulthood. Guilford Press.

Soldz B, Vaillant G (1999) The Big 5 and the life course: a 45 year longitudinal study. Journal of Research into Personality 33: 208-32.

Sowell E, Thompson P, Holmes C, et al (1999) In vivo evidence for postadolescent brain maturation in frontal and striatal regions. Nature Neuroscience 2: 859-61

Sunderland M (2006) The Science of Parenting: Practical Guidance on Sleep, Crying, Play and Building Emotional Well Being for Life. Dorling Kindersley

Tappan M (1989) Stories lived and stories told: the narrative structure of late adolescent moral development. Human Development 32: $300-15$

Trupin E, Stewart DE, Beach B, et al (2002) Effectiveness of a dialectical behaviour therapy program for incarcerated female juvenile offenders. Child and Adolescent Mental Health 7: 121-7.

Tyrer P, Johnson T (1996) Establishing the severity of personality disorder. American Journal of Psychiatry 153: 593-7.

Vaillant G (1983) The Wisdom of the Ego. Harvard University Press.

Vizard E, French L, Hickey N, et al (2004) Severe personality disorder emerging in childhood: a proposal for a new developmental disorder. Criminal Behaviour \& Mental Health 14: 17-28.

Werner E (1993) Risk, resilience and recovery: perspectives from the Kauai Study. Development and Psychopathology 5: 503-15.

Westen D, Thomas C, Nakash 0, et al (2006) Clinical assessment of attachment and personality disorder in adolescence and adulthood. Journal of Consulting and Clinical Psychology 74: 1065-85.

Wolff S, Acton WP (1968) Characteristics of parents of disturbed children. British Journal of Psychiatry 114: 593-601.

\section{MCOs}

Select the single best option for each question stem

1 Personality disorder in adolescence:

a is easily diagnosed

b does not exist

c is exactly the same as adult personality disorder

$d$ is only found in in-patient settings

e is often comorbid with Axis I disorders

2 The prevalence of personality disorder in adolescence:

a is the same as adult rates

$\mathrm{b}$ is the same in in-patient and community settings

c changes over time d cannot be estimated reliably

e finds rates of $17 \%$ for severe disorders.

3 Personality disorder in adolescence:

$a$ is genetically determined

b has no association with adult disorders

c does not increase the risk of violence

$\mathrm{d}$ is associated with child-rearing problems in adulthood

e is untreatable.

4 Which of the following is not an established treatment for personality disorder in adolescence?

a dialectical behaviour therapy

b STEPPS

c multisystmeic therapy d mentalisation-based therapy

e family therapy.

5 Determinants of personality disorder in adolescence do not include:

a diet

b genetic vulnerability

c parental psychopathology

d childhood adversity

e childhood neuroticism. 